\title{
Development of an Inoculation Technique and the Evaluation of Soybean Genotypes for Resistance to Coniothyrium glycines
}

Paul W. Tooley, United States Department of Agriculture-Agricultural Research Service, Foreign Disease-Weed Science Research Unit, Ft. Detrick, MD 21702-5023

\begin{abstract}
Red leaf blotch, caused by Coniothyrium glycines, is a serious disease affecting soybean in several African countries but has not yet appeared in the United States. The fungal pathogen is listed as a Select Agent by the Federal Select Agent Program because of potential consequence to U.S. agriculture if introduced. Sources of resistance to red leaf blotch have not yet been identified in spite of extensive field testing in Zambia and Zimbabwe. A seedling inoculation protocol was used to investigate the effects of inoculum density, temperature $\left(20\right.$ and $\left.25^{\circ} \mathrm{C}\right)$, and dew chamber incubation period ( 2 to 5 days) on disease development in 'Williams 82' soybean. Inoculum

density and incubation period had significant effects on disease severity but no significant difference was observed at 20 and $25^{\circ} \mathrm{C}$. Highest levels of disease were obtained using $1.94 \mathrm{~cm}^{3}$ of mycelial inoculum per $10 \mathrm{ml}$ of water and incubating plants for 5 days at $100 \%$ relative humidity. Significant differences were not observed between isolates from Zambia and Zimbabwe at $25^{\circ} \mathrm{C}$. In total, 23 soybean genotypes that represent nearly $90 \%$ of the genes present in U.S. soybean were evaluated and found to be susceptible, which is consistent with previous field evaluations. This method could be useful in identifying new sources of resistance to red leaf blotch.
\end{abstract}

Red leaf blotch of soybean is a serious disease that causes blotching and defoliation of soybean (Glycine $\max (\mathrm{L}$.) Merr.) and a wild legume, Neonotonia wightii. The cause of the disease was first reported as Pyrenochaeta glycines (Stewart 1957) in Ethiopia. Since then, it has been reported in several Eastern, Central, and Southern African countries (Akem et al. 1992; Hartman et al. 1987; Levy et al. 1990). In 2002, the pathogen was renamed Phoma glycinicola (de Gruyter and Boerema 2002) because conidiogenesis and hyaline conidia were phoma-like. However, the most current reexamination of the species (de Gruyter et al. 2013) determined that classification in the genus Coniothyrium was justified, because it was noted by Stewart (1957) that the conidia were greenish-yellow in mass, resembling coniothyrium-like conidia.

Sinclair (1989) observed that, even though the disease had been restricted to several African countries, he believed it had the potential to become a major foliar soybean disease if the pathogen were to spread to other parts of the world. Red leaf blotch has been deemed a potentially devastating disease for soybean production (Hartman et al. 2011). For these reasons, Coniothyrium glycines is currently listed as one of the United States Department of Agriculture (USDA) Plant Protection and Quarantine Select Agents and Toxins (Federal Select Agent Program 2014; Hartman et al. 2009).

Red leaf blotch is known to cause serious soybean losses in the field (Datnoff et al. 1987; Hartman et al. 1987; Levy 1987), and it was observed (Sinclair 1989) that all commercial U.S. cultivars tested in Zambia and Zimbabwe between 1982 and 1984 were susceptible. No resistance was noted among local lines or about 5,500 exotic soybean lines tested (Levy et al. 1990). All cultivars and breeding lines tested thus far have been tested in the field in regions where the disease is endemic, requiring resources including land and the presence of natural inoculum sources. A suitable seedling inoculation method for red leaf blotch of soybean would be highly

Corresponding author: P. W. Tooley; E-mail: paul.tooley@ars.usda.gov

Mention of trade names or commercial products in this publication is solely for the purpose of providing specific information and does not imply recommendation or endorsement by the U.S. Department of Agriculture. USDA is an equal opportunity provider and employer.

Accepted for publication 14 April 2017.

This article is in the public domain and not copyrightable. It may be freely reprinted with customary crediting of the source. The American Phytopathological Society, 2017. desirable for defining conditions that allow optimal infection and, ultimately, for testing additional germplasm for susceptibility. Such a method would require less space and could be performed far more efficiently than field studies that rely on the occurrence of natural inoculum.

The objective of this study was to develop an inoculation protocol for red leaf blotch based on assessments of temperature (20 versus $25^{\circ} \mathrm{C}$ ), inoculum density, and incubation period at $100 \%$ relative humidity using 'Williams 82' soybean. The two temperatures were compared because both have been used by other workers (Hartman and Sinclair 1992; Levy 1987). The optimal method was further used to evaluate 23 ancestral U.S. cultivars and breeding lines for resistance to $C$. glycines.

\section{Materials and Methods}

Isolates and plant material. Isolates of $C$. glycines used included IMI 294986 (= P. glycinicola Gruyter \& Boerema) (de Gruyter and Boerema 2002) (isolated from G. $\max$ at Mt. Makulu, Zambia in 1985), Pg-1 (isolated from G. max collected in Harare, Zimbabwe in 2001), Pg-21 (isolated from G. max collected in Harare, Zimbabwe in 2005), Pg-31 (isolated from G. max collected at Chisamba, Zambia in 2005), and Pg-41 (isolated from G. max collected at Mpongwe, Zambia in 2005). Isolations were made onto $2 \%$ water agar from field material obtained from colleagues in Zambia and Zimbabwe. C. glycines cultures were maintained on $20 \%$ V8-juice agar at $20^{\circ} \mathrm{C}$ in darkness. Ancestral soybean lines were obtained from Randy Nelson, USDA soybean germplasm collection, Urbana, IL. The selected lines account, by pedigree, for nearly $90 \%$ of the genes present in modern public soybean cultivars.

Inoculum production and plant inoculations. Soybean plants were grown in 15.2-cm-diameter plastic pots filled with Sunshine LC1 mix (Sun Grow Horticultural Products, Belleview, WA) and fertilized as needed with 14-14-14 Osmocote (Scotts-Sierra Horticultural Products Co., Marysville, $\mathrm{OH}$ ). To produce inoculum, a square (1.94 $\mathrm{cm}^{3}$, except for inoculum density experiments) cut from a 10 day-old $20 \%$ V8-juice agar culture of $C$. glycines containing mycelium as well as numerous sclerotia was ground in a Tenbroeck-type glass tissue grinder (Kimble/Kontes, Vineland, $\mathrm{NJ}$ ) with $10 \mathrm{ml}$ of sterile water until all lumps were removed. The ground mycelial suspension ( $1 \mathrm{ml} /$ plate) was spread onto plates of $20 \%$ V8-juice agar containing $15 \mathrm{ml}$ of medium per 9-cm-diameter disposable plastic Petri dish. The $15-\mathrm{ml}$ volume produced a thin ( $3 \mathrm{~mm}$ deep) agar surface in the Petri dishes, and the inoculated dishes were incubated at $20^{\circ} \mathrm{C}$ for 5 days in darkness. Then, various sized squares or rectangles of agar containing mycelium and small, numerous young sclerotia were cut 
out from the thin plates and ground in a glass tissue grinder with $10 \mathrm{ml}$ of sterile water per the indicated volume of inoculum, until no lumps remained. Soybean plants (approximately 2 weeks old) were sprayed to runoff with the homogenized inoculum using a 480-ml-capacity industrial spray bottle (Lab Safety Supply, Janesville, WI) with the tube extended into a 50-ml disposable conical centrifuge tube containing the inoculum suspension. Williams 82 was used as a susceptible control.

Dew chamber time of incubation. Three replicates of an experiment were performed to determine the number of days of postinoculation dew chamber incubation for Williams 82 soybean to exhibit the most pronounced degree of symptom development following inoculation with $C$. glycines. In each replicate experiment, single trifoliates (consisting of three leaflets) on one plant per 15.2-cm-diameter plastic pot were inoculated as described above using $C$. glycines isolate IMI 294986 at a density of $1.94 \mathrm{~cm}^{3}$ of agar inoculum per $10 \mathrm{ml}$ of water. Inoculated plants were placed in a dew chamber at $25^{\circ} \mathrm{C}$ in a completely random design and three plants (containing a total of nine inoculated leaflets) were removed after periods of 2, 3, 4, or 5 days. Following more than 5 days of incubation, leaf yellowing and lesion coalescence began to occur, making results more difficult to assess. Due to space constraints, control plants were inoculated using agar inoculum minus the pathogen and were placed on a $25^{\circ} \mathrm{C}$ greenhouse bench at time zero and not subjected to dew chamber treatment. Plants removed from the dew chamber were allowed to dry, and the infected leaves were then scanned with a flatbed scanner. Leaf and lesion areas were determined using the ASSESS software program (Lamari 2002). Percent leaf area infected was calculated as (lesion area/leaf area) $\times 100$.

Inoculum density-temperature. To produce varying inoculum density, the volume removed from the thin agar plates of $C$. glycines isolate IMI 294986 mycelium and sclerotia described above was altered to produce quantities higher and lower than that used for the days in the dew chamber experiment. The volume of agar inoculum used in the days in dew chamber experiment $\left(1.94 \mathrm{~cm}^{3}\right.$ of agar inoculum per $10 \mathrm{ml}$ of water) was again used in these experiments (again, three replicate experiments were performed) but was also doubled to $3.87 \mathrm{~cm}^{3}$ per $10 \mathrm{ml}$ of water and, in addition, was cut in half and in half again, yielding, 0.97 and $0.48 \mathrm{~cm}^{3}$ per $10 \mathrm{ml}$ of water, respectively. Controls received only water. Soybean plants were grown three to a 15.2-cm-diameter plastic pot for approximately 2 weeks and, in each replicate factorial experiment, a single trifoliate on the three plants in each of four pots was inoculated with each inoculum density. Thus, nine leaflets were inoculated in each pot for each treatment, and two replicate pots were included in each of three replicate experiments. Two pots of plants inoculated with each inoculum density were placed in a $20^{\circ} \mathrm{C}$ dew chamber and the other two placed in a $25^{\circ} \mathrm{C}$ dew chamber for 5 days, after which time disease was assessed. All plants were assessed at the same number of days after inoculation. This yielded 18 leaflets/treatment/experiment and 54 leaflets/ treatment total for the three replications. After 5 days of incubation in the dew chambers, infected leaves were removed and scanned on a flatbed scanner, and leaf and lesion areas were quantified using the ASSESS software package (Lamari 2002). Percent leaf area infected was calculated as (lesion area/leaf area) $\times 100$.

Table 1. Analysis of variance for percent Williams 82 soybean leaf area infected by Coniothyrium glycines following incubation in a dew chamber at $100 \%$ relative humidity for $0,2,3,4$, and 5 days

\begin{tabular}{lrc}
\hline Source & DF & $\boldsymbol{P}$ value \\
\hline Experiment $(\text { Exp })^{\mathrm{z}}$ & 2 & 0.249 \\
Days in dew chamber & 4 & 0.000 \\
Exp $\times$ days in dew chamber & 8 & 0.322 \\
Error & 120 & $\ldots$ \\
Total & 134 & $\ldots$ \\
\hline
\end{tabular}

${ }^{\mathrm{z}}$ Three replicate experiments were performed in which single trifoliates (consisting of three leaflets) on one plant per pot were inoculated using C. glycines isolate IMI294986 at an inoculum density of $1.94 \mathrm{~cm}^{3}$ of agar inoculum per $10 \mathrm{ml}$ of water. Nine leaflets were inoculated/treatment/replicate experiment.
Greenhouse inoculations. Due to space constraints in dew chambers as well as lack of lighting, which resulted in some chlorosis occurring on plants during incubation periods, it was desirable to perform inoculation studies in a greenhouse environment. Wooden lumber ( 35 by $19 \mathrm{~mm}$ ) was used to construct a three-dimensional wooden framework measuring $119 \mathrm{~cm}$ long by $46 \mathrm{~cm}$ wide by $61 \mathrm{~cm}$ high, and this framework was covered with clear 4-mil plastic sheeting to allow light to enter. The structure was left open at the bottom so that it could be raised and lowered over potted plants on a greenhouse bench. Two layers of black plastic sheeting were placed on the greenhouse bench below the plants to allow a moisture seal when the structure was placed over the plants. At one end of the structure, a hole was made near the top to allow insertion of a 3.81-cm-diameter flexible plastic pipe. The pipe was used to conduct mist into the humidity structure generated by a Germ Guardian ultrasonic digital humidifier (model number H3010; Guardian Technologies LLC, Mentor, OH). The water reservoir on the humidifier was refilled daily to allow continuous use during experiments. Yellowing was not a problem in the greenhouse moist chamber, because plants received continual sunlight. The greenhouse assay was used to evaluate the disease reactions of Williams 82 soybean inoculated with five different isolates of $C$. glycines, and to evaluate 23 ancestral soybean lines. Each of the two types of experiments were completed three times, and were performed in a level BSL-3 containment greenhouse at $25^{\circ} \mathrm{C}$ on a greenhouse bench using a completely random design. For $C$. glycines isolate comparisons, inoculum of isolates IMI294986, Pg-1, Pg-21, $\mathrm{Pg}-31$, and Pg-41 was produced as described above, using $1.94 \mathrm{~cm}^{3}$ of inoculum per $10 \mathrm{ml}$ of water and spraying Williams 82 soybean to runoff. In each replicate experiment, three trifoliates (nine leaflets) in two pots of approximately 2-week-old Williams 82 soybean were inoculated with each isolate ( $n=18$ leaflets/isolate/experiment). To evaluate soybean lines, 10 trifoliates of each cultivar were inoculated in each of three replicate experiments $(n=30$ leaflets/cultivar/ experiment). For each cultivar, several infected leaf pieces were disinfested in $1 \%$ sodium hypochlorite for 1 to $2 \mathrm{~min}$ and plated onto plates of $2 \%$ water agar to confirm reisolation of $C$. glycines from the symptomatic material.

Statistical analyses. Data from the three repeated experiments were pooled and analyzed via analysis of variance using the General Linear Models procedure, as well as by linear and polynomial regression analysis in SAS (SAS Institute 2008) and Minitab (Minitab 2010).

\section{Results}

Dew chamber time of incubation. Symptoms were observed 2 days after inoculation and reached their highest level after 5 days. Mean percent leaf area infected for $0,2,3,4$, and 5 days in the dew chamber was $0,0.9,3.9,11.6$, and $17.8 \%$, respectively. Analysis of variance (Table 1) showed that there was no significant $(P=0.05)$ experiment-to-experiment variation, nor was there a significant experiment-days in dew chamber interaction. However, highly significant differences $(P<0.001)$ were observed between days in the dew chamber. A dew chamber treatment of 5 days at $100 \%$ relative humidity resulted in the highest levels of disease (Fig. 1). The relationship between days in the dew chamber and percent leaf area infected was determined using polynomial regression analysis, and it was found that both the linear and quadratic terms were highly significant $(P<0.01)$. Thus, a quadratic equation best described the trend in the data. The best-fitting regression equation to describe the relationship was percent leaf area infected $=-0.0943-1.552$ (days in dew chamber) +1.046 (days in dew chamber $)^{2}$, with an adjusted $r^{2}$ value of $90.2 \%$.

Inoculum density and temperature. For the lowest inoculum level used $\left(0.48 \mathrm{~cm}^{3}\right.$ of inoculum per $10 \mathrm{ml}$ of water $)$, a $8.6 \%$ leaf area infected was obtained on Williams 82 soybean at $20^{\circ} \mathrm{C}$ and $9.5 \%$ at $25^{\circ} \mathrm{C}$. Disease increased up to $18.3 \%$ leaf area infected at the inoculum concentration of $1.94 \mathrm{~cm}^{3}$ of inoculum per $10 \mathrm{ml}$ of water at $20^{\circ} \mathrm{C}$ and $18.6 \%$ at $25^{\circ} \mathrm{C}$, then decreased slightly at the highest inoculum concentration of $3.87 \mathrm{~cm}^{3}$ of inoculum per $10 \mathrm{ml}$ of water (Fig. 2). Thus, the relationship between inoculum density and disease was 


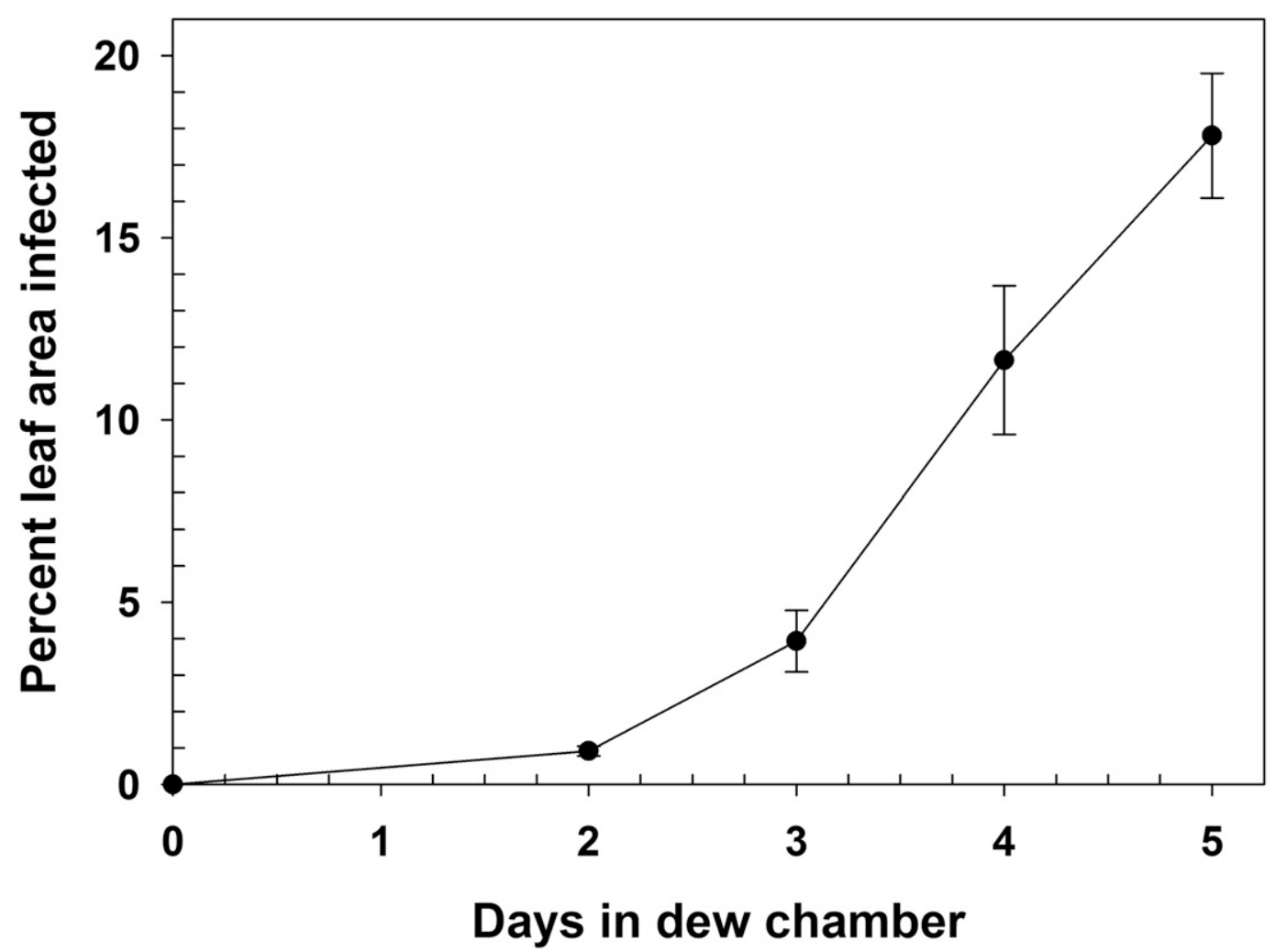

Fig. 1. Effect of incubation time on percent leaf area infected for Williams 82 soybean inoculated with Coniothyrium glycines incubated in a dew chamber at $100 \%$ relative humidity at $25^{\circ} \mathrm{C}$. Bars represent standard errors.

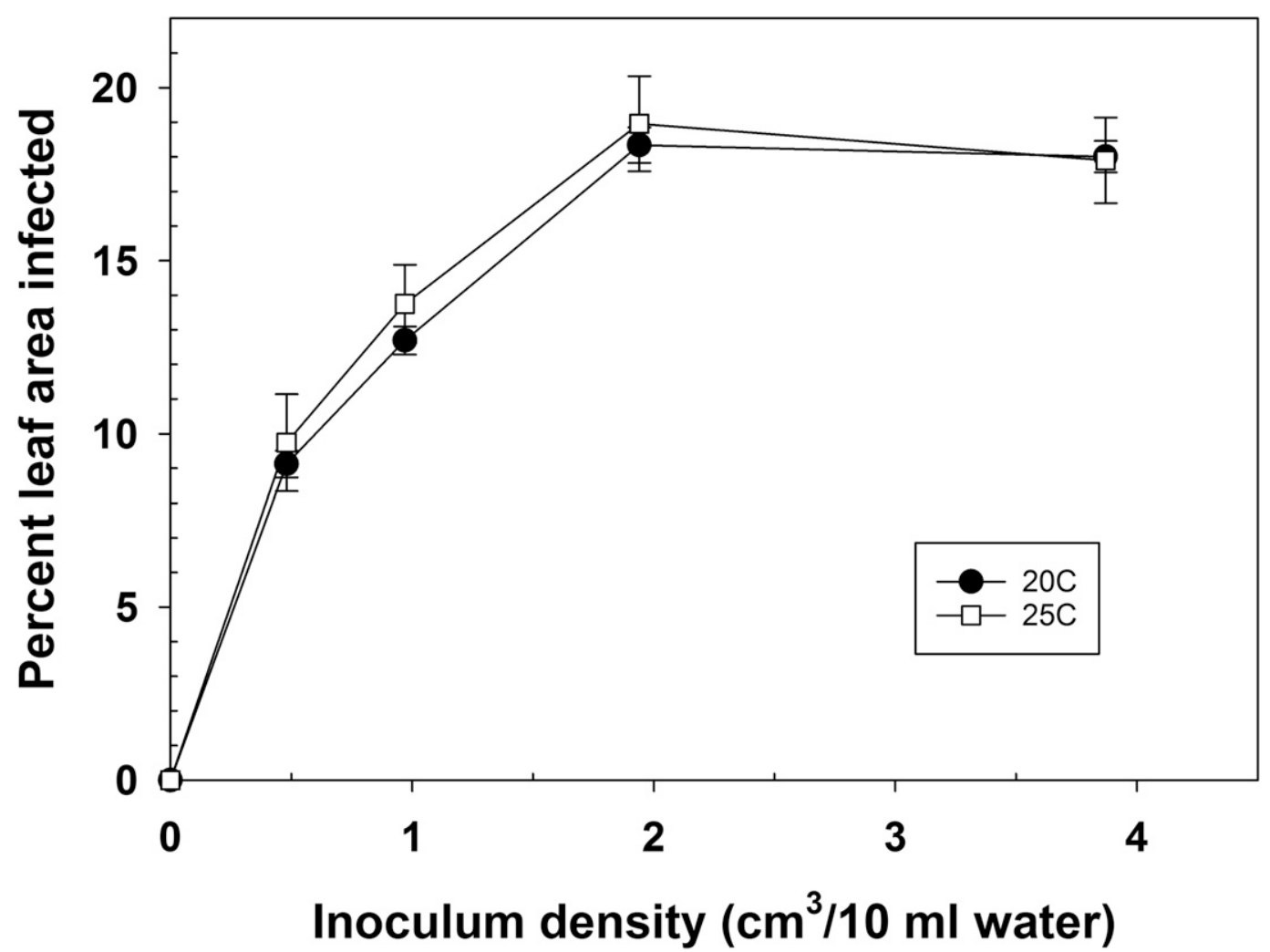

Fig. 2. Percent leaf area infected for Williams 82 soybean as a function of temperature $\left(20\right.$ and $\left.25^{\circ} \mathrm{C}\right)$ and inoculum density. Inoculum density values were expressed in terms of the volume of agar inoculum $\left(0,0.48,0.97,1.94\right.$, or $\left.3.87 \mathrm{~cm}^{3}\right)$ per $10 \mathrm{ml}$ of water applied to plants by spraying to runoff. Bars represent standard errors. 
curvilinear (Fig. 2), and was found to have highly significant $(P<$ $0.001)$ linear and quadratic components. The regression equation that best fit the $20^{\circ} \mathrm{C}$ data (adjusted $r^{2}=82.7 \%$ ) was percent leaf area infected $=1.142+4.431$ (inoculum density) -0.2476 (inoculum density $)^{2}$. For the $25^{\circ} \mathrm{C}$ data, the corresponding equation was percent leaf area infected $=1.321+4.684$ (inoculum density) 0.2700 (inoculum density) ${ }^{2}$, with an adjusted $r^{2}$ value of $83.4 \%$. Analysis of variance was performed (Table 2$)$ and highly significant $(P<$ $0.001)$ effects were observed for inoculum density. Significance was not observed for the factors experiment, temperature, or the interaction of inoculum density and temperature (Table 2).

Five-isolate comparison in greenhouse at $25^{\circ} \mathrm{C}$. Analysis of variance showed no significant differences $(P=0.05)$ among experiments or among $C$. glycines isolates, nor was there a significant experiment-isolate interaction. Mean percent leaf area infected on Williams 82 soybean for isolates IMI 294986, Pg-1, Pg-21, Pg-31, and Pg-41was 19.7, 17.7, 20.1, 19.9, and 18.2\%, respectively.

Reactions of soybean lines. The reactions of 23 ancestral soybean lines to C. glycines isolate IMI 294986 at $25^{\circ} \mathrm{C}$ in a humidity chamber located in a level BSL-3 containment greenhouse are shown in Table 3 (Fig. 3). Soybean cultivars tested did not differ significantly from one another in percent infected leaf area using the Tukey method and a $95 \%$ joint confidence level (Table 3 ).

\section{Discussion}

This study describes the use of ground mycelium and sclerotia to inoculate soybean with $C$. glycines. Previous red leaf blotch workers have performed inoculations of soybean leaves or leaf disks by using agar plugs or spraying leaf surfaces with a suspension of conidia (Datnoff et al. 1986), by applying mycelial disks to leaflets (Hartman and Sinclair 1992), or by applying droplets of a suspension made from macerating pycnidia-producing, 21-day-old culture plugs to leaflets (Levy 1987). For other sclerotia-forming fungi, Faske et al. (2006) evaluated several types of inoculum in studies of Sclerotinia minor on peanut, including use of germinating sclerotia on peanut stems, 3-day-old dry mycelia, perlite granules coated with mycelial fragments, and mycelial agar plug inoculum and observed that all types of inoculum resulted in similar lesion development. A mixture of sclerotia and mycelium was used successfully for inoculation of lettuce with S. minor (Grube and Ryder 2004), while conidia were sprayed onto plants of faba bean for infection by Botrytis fabae (Tivoli et al. 2006). For S. sclerotiorum on soybean, foliar inoculations have been performed using mycelial disks (Chun et al. 1987), mycelial squares grown on sterile paper (Nelson 1985), and by spraying ascospores and placing pieces of colonized carrot pieces onto leaf surfaces (Cline and Jacobsen 1983). The method described in this article with $C$. glycines on soybean worked consistently, was reproducible and quantifiable, and does not rely on production and collection of conidia or other spore types to generate inoculum.

The concentration of inoculum which resulted in the highest disease levels was $1.94 \mathrm{~cm}^{3}$ of ground agar inoculum (containing mycelium as well as abundant sclerotia) per $10 \mathrm{ml}$ of water.

Table 2. Analysis of variance for percent Williams 82 soybean leaf area infected by Coniothyrium glycines as a function of temperature (20 and $25^{\circ} \mathrm{C}$ ) and inoculum density

\begin{tabular}{lrc}
\hline Source & DF & $\boldsymbol{P}$ value \\
\hline Experiment $^{\mathrm{z}}$ & 2 & 0.504 \\
Temperature (Temp) & 1 & 0.076 \\
Inoculum density & 4 & 0.000 \\
Temp $\times$ inoculum density & 4 & 0.545 \\
Error & 528 & $\ldots$ \\
Total & 539 & $\ldots$ \\
\hline
\end{tabular}

${ }^{\mathrm{z}}$ Eighteen leaflets were inoculated with C. glycines isolate IMI 294986/treatment/replicate experiment, and 54 leaflets/treatment total for the three experiments performed. Five different inoculum densities were used, including the control. After 5 days of incubation in dew chambers at 20 or $25^{\circ} \mathrm{C}$, infected leaves were removed and scanned on a flatbed scanner. Percent leaf area infected was calculated as (lesion area/leaf area) $\times 100$.
Increasing the inoculum level to $3.87 \mathrm{~cm}^{3}$ of inoculum per $10 \mathrm{ml}$ of water resulted in a slight decline in disease levels compared with the $1.94 \mathrm{~cm}^{3}$ amount, perhaps due to saturation of infection sites on the soybean leaves or other inhibitory effects due to the increased volume of agar present in the liquefied inoculum.

Hartman and Sinclair (1992) performed cultural studies with C. glycines at both 20 and $25^{\circ} \mathrm{C}$ and showed that pycnidiospore germination occurred almost equally at these two temperatures. They also conducted detached-leaf inoculation studies at $25^{\circ} \mathrm{C}$. Levy (1987) performed numerous cultural studies with the fungus at a temperature of $25^{\circ} \mathrm{C}$. Thus, incubation temperatures $\left(20\right.$ versus $\left.25^{\circ} \mathrm{C}\right)$ were compared for inoculation of soybean with $C$. glycines because both temperatures had been used in previous studies. No significant difference was observed in percent leaf area infected for Williams 82 soybean incubated at 25 versus $20^{\circ} \mathrm{C}$, indicating that $C$. glycines can infect over a range of temperatures. In the studies of Hartman and Sinclair (1992), it was found that pycnidiospore germination of $C$. glycines was nearly equal at 20 versus $25^{\circ} \mathrm{C}$ and even though many of their studies, including detached-leaf inoculation studies, were performed at $25^{\circ} \mathrm{C}$, other studies such as growth on various $\mathrm{NaCl}$ concentrations amended in Bacto agar and studies of pycnidia and sclerotia production on detached-leaf disks were performed at $20^{\circ} \mathrm{C}$. Because the pathogen can grow and infect soybean over a range of temperatures, it has the potential to become established in more diverse regions of the United States compared with pathogens having a narrower temperature range.

Table 3. Mean percent infected leaf area for whole plants of soybean cultivars inoculated with Coniothyrium glycines in a containment greenhouse ${ }^{\mathrm{w}}$

\begin{tabular}{lrlcc}
\hline Cultivar name & PIy & Origin & $\begin{array}{c}\text { Maturity } \\
\text { group }\end{array}$ & $\begin{array}{c}\text { Mean leaf } \\
\text { area } \\
\text { infected }(\%)\end{array}$ \\
\hline Ogden & 548477 & China, Japan & VI & $20.1 \mathrm{a}$ \\
Haberlandt & 548456 & North Korea & VI & $19.9 \mathrm{a}$ \\
Williams 82 & 518671 & Unknown & III & $19.6 \mathrm{a}$ \\
Roanoke & 548485 & China & VII & $19.6 \mathrm{a}$ \\
Anderson & 33243 & Unknown & IV & $19.5 \mathrm{a}$ \\
Illini & 548348 & China & III & $19.3 \mathrm{a}$ \\
Jackson & 548657 & China, Japan & VII & $19.3 \mathrm{a}$ \\
Ralsoy & 548484 & North Korea & VI & $19.3 \mathrm{a}$ \\
Mandarin & 548379 & China & 0 & $19.2 \mathrm{a}$ \\
(Ottawa) & & & & \\
A.K. (Harrow) & 548298 & China & III & $19.1 \mathrm{a}$ \\
Bansei & 548302 & Japan & II & $19.1 \mathrm{a}$ \\
Perry & 548603 & China & IV & $18.9 \mathrm{a}$ \\
Mukden & 548391 & China & II & $18.7 \mathrm{a}$ \\
CNS & 548445 & China & VII & $18.6 \mathrm{a}$ \\
Dunfield & 548318 & China & III & $18.4 \mathrm{a}$ \\
Capital & 548311 & China & 0 & $18.3 \mathrm{a}$ \\
Lincoln & 548362 & China & III & $18.2 \mathrm{a}$ \\
Bossier & 567789 & Unknown & VIII & $17.9 \mathrm{a}$ \\
Kanro & 548356 & North Korea & II & $17.9 \mathrm{a}$ \\
S-100 & 548488 & China & V & $17.9 \mathrm{a}$ \\
Fiskeby 840-7-3 & 438477 & Sweden & 00 & $17.8 \mathrm{a}$ \\
Manitoba Brown & 548382 & Canada & 00 & $17.8 \mathrm{a}$ \\
Richland & 548406 & China & II & $17.3 \mathrm{a}$ \\
Flambeau & 548325 & Russia & 00 & $17.2 \mathrm{a}$ \\
\hline Soybean & & 23 & & \\
\hline
\end{tabular}

${ }^{\text {w }}$ Soybean lines consisted of 23 ancestral U.S. soybean genotypes plus Williams 82.

$x$ Whole plants were inoculated with ground mycelium and sclerotia at a density of $1.94 \mathrm{~cm}^{3}$ of agar inoculum per $10 \mathrm{ml}$ of water and placed in a moist chamber at $100 \%$ relative humidity and $25^{\circ} \mathrm{C}$ for 5 days. Experiments were performed in a Biosafety Level 3 containment greenhouse, United States Department of Agriculture-Agricultural Research Service, Fort Detrick, MD.

y Plant introduction number.

${ }^{z}$ Means within a column followed by the same letter do not differ significantly according to the Tukey method using a $95 \%$ joint confidence level. Data are means of three replicate experiments, each containing 10 inoculated trifoliates per cultivar. 
Datnoff et al. (1987) reported 'Jupiter' and 'Tunia' soybean to have some resistance to red leaf blotch in the field in Zambia. Even though they were reported to show lower disease severity, vertical disease progress, and area under the disease progress curve compared with 'Geduld', 'Magoye', 'Oribi', and 'Sable', disease severity (expressed as the percentage of the total leaf area diseased at growth stages R5 to R6) was still quite high and was reported as $21 \%$ for Jupiter and $16 \%$ for Tunia. A later study (Hartman and Sinclair 1996) reported that Tunia was susceptible, with defoliation percentages of 43 to $57 \%$ in unsprayed plots in two growing seasons in Zambia. Reports of resistance to red leaf blotch had not been confirmed in additional studies and Sinclair (1989) reported that all commercial U.S. cultivars tested in Zambia and Zimbabwe between 1982 and 1984 were susceptible. The U.S. soybean germplasm tested was uniformly susceptible to red leaf blotch as determined by the described seedling inoculation method. This result is consistent with results obtained from field studies performed in regions of the world where red leaf blotch is endemic (Datnoff et al. 1987; Levy et al. 1990; Sinclair 1989). Hopefully, some level of resistance can be identified in additional soybean genotypes, for there exist over 32,500 soybean germplasm accessions (USDA-ARS 2017), most of which have not been evaluated for their susceptibility to red leaf blotch (Hartman 2014; Hartman et al. 2009).

In the detached-leaf studies of Hartman and Sinclair (1992), percent leaf area infected ranged from 2 to $98 \%$ for the various host species tested whereas, in our studies, mean percent leaf area infected was generally less than $20 \%$. The differences in the studies that could account for the varying percentages are that, in the studies of Hartman and
Sinclair (1992), leaves were incubated for periods of 2 weeks for determination of leaf infection whereas, in our studies, leaf infection was assessed after 5 days. If plants would have been incubated longer following the 5-day treatment at $100 \%$ relative humidity, lesions would have expanded and higher percentages of infected leaf area would have undoubtedly been obtained. However, in preliminary studies, it was observed that leaf curling and dropping tended to occur if plants were left to incubate longer in the greenhouse following high-humidity treatment; therefore, the most consistent and reliable results were to be obtained by determining infection percent following removal from dew or humidity chambers.

No differences were found among isolates from Zambia and Zimbabwe in their ability to infect Williams 82 soybean at $25^{\circ} \mathrm{C}$. Isolates from additional geographic regions from which $C$. glycines has been reported to infect soybean (such as Nigeria and Bolivia) should be tested as well, and an evaluation of the genetic variability present within the pathogen performed using molecular markers to determine whether the pathogen population is homogeneous or contains genetic variation for pathogenicity and other characteristics.

Additional studies are necessary to evaluate genetic variability within the pathogen population from different countries where it occurs, and to evaluate additional soybean accessions in the search for resistance to red leaf blotch to be deployed should the pathogen become established in the United States. Further studies are also required to determine the temperature limits for infection and survival of $C$. glycines so that its threat potential can be more accurately determined.

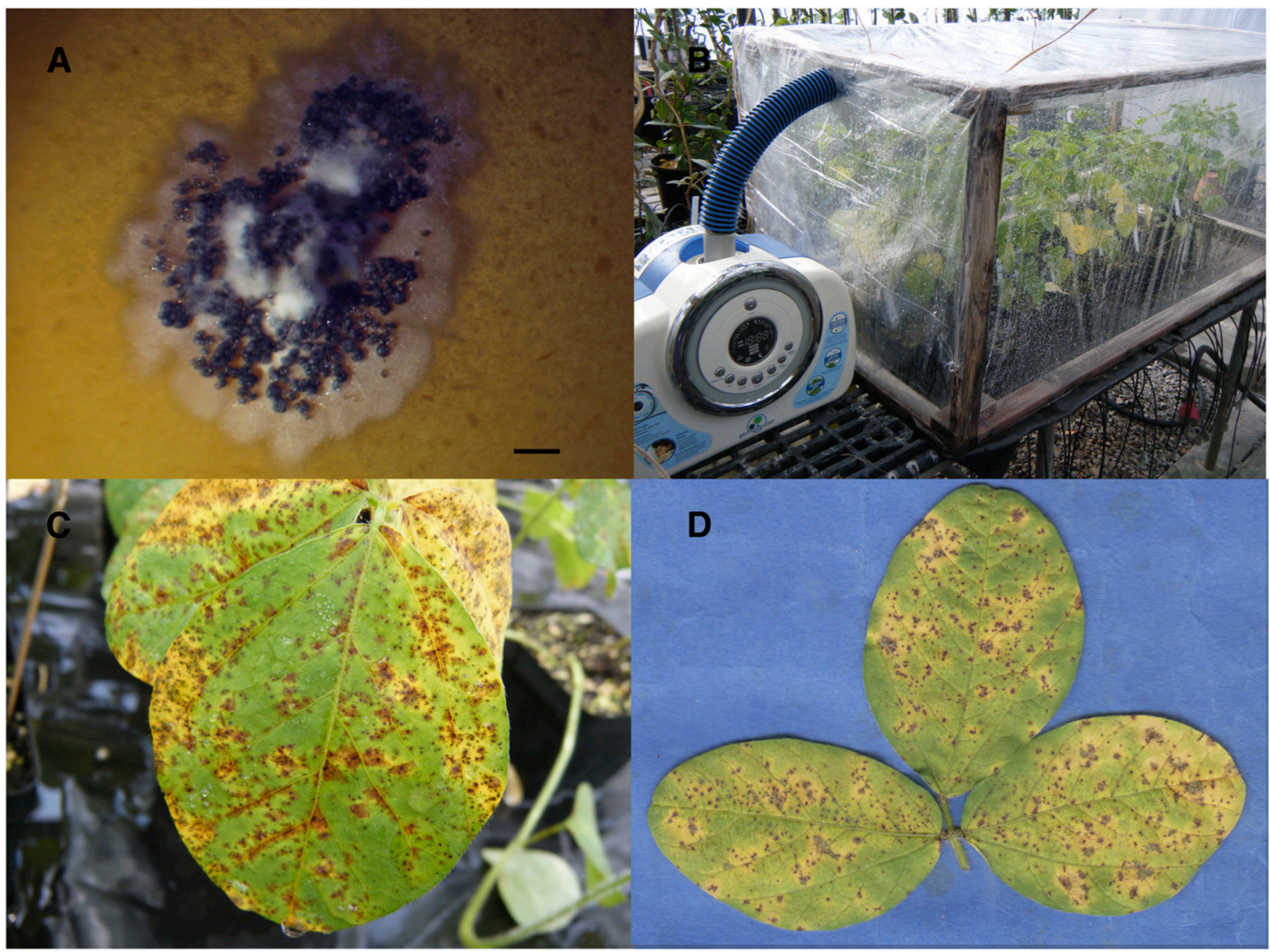

Fig. 3. A, Culture of Coniothyrium glycines (14 days old) growing on 20\% V8-juice agar (scale bar represents $2 \mathrm{~mm}$ ); B, humidity chamber set up in containment greenhouse for inoculation of soybean with C. glycines. C and D, Symptoms from inoculation of Williams 82 (C) and Fiskeby 840-7-3 (D) soybean using humidity chamber in a containment greenhouse. 


\section{Acknowledgments}

We thank M. Carras for technical assistance in these studies; R. Nelson, USDA soybean germplasm collection, Urbana, IL and G. Hartman, USDA-ARS, Urbana, IL for providing seed of the soybean lines used in these studies; and C. Levy and J. Tichagwa for providing diseased soybean leaves from Zimbabwe and Zambia from which isolations of $C$. glycines were made.

\section{Literature Cited}

Akem, C. N., Akueshi, C. O., Agina, S. M., and Dashiell, K. E. 1992. Pyrenochaeta glycines, a threat to soybean cultivation in Nigeria. Int. J. Trop. Plant Dis. 10:95-97.

Chun, D., Kao, L. B., and Lockwood, J. L. 1987. Laboratory and field assessment of resistance in soybean to stem rot caused by Sclerotinia sclerotiorum. Plant Dis. 71:811-815.

Cline, M. N., and Jacobsen, B. J. 1983. Methods for evaluating soybean cultivars for resistance to Sclerotinia sclerotiorum. Plant Dis. 67:784-786.

Datnoff, L. E., Levy, C., Naik, D. M., and Sinclair, J. B. 1986. Dactuliophora glycines, a sclerotial state of Pyrenochaeta glycines. Trans. Br. Mycol. Soc. 87:297-301.

Datnoff, L. E., Naik, D. M., and Sinclair, J. B. 1987. Effect of red leaf blotch on soybean yields in Zambia. Plant Dis. 71:132-135.

de Gruyter, J., and Boerema, G. H. 2002. Contributions toward a monograph of Phoma (Coelomycetes) VIII. Section Paraphoma: Taxa with setose pycnidia. Persoonia 17:541-561.

de Gruyter, J., Woudenberg, J. H. C., Aveskamp, M. M., Verkley, G. J. M., Groenewald, J. Z., and Crous, P. W. 2013. Redisposition of phoma-like anamorphs in Pleosporales. Stud. Mycol. 75:1-36.

Faske, T., Melouk, H. A., and Payton, M. E. 2006. Comparison of Sclerotinia minor inocula for differentiating the reaction of peanut genotypes to Sclerotinia blight. Peanut Sci. 33:7-11.

Federal Select Agent Program. 2014. Select agents and toxins list. Online publication. Animal and Plant Health Inspection Service, Agriculture Select Agent Services, Riverdale, MD 20737. https://www.selectagents.gov/SelectAgentsandToxinsList. $\mathrm{html}$

Grube, R., and Ryder, E. 2004. Identification of lettuce (Lactuca sativa L.) germplasm with genetic resistance to drop caused by Sclerotinia minor. J. Am. Soc. Hortic. Sci. 129:70-76.

Hartman, G. L. 2014. Phoma glycinicola. Pages 801-806 in: Manual of Security Sensitive Microbes and Toxins. D. Liu, ed. CRC Press, Taylor and Francis, Boca Raton, FL.
Hartman, G. L., Datnoff, L. E., Levy, C., Sinclair, J. B., Cole, D. L., and Javaheri, F. 1987. Red leaf blotch of soybeans. Plant Dis. 71:113-118.

Hartman, G. L., Haudenshield, J., Smith, K. L., Tooley, P., Shelton, J., Bulluck, R, Engle, J. S., and Magarey, R. D. 2009. Recovery plan for red leaf blotch of soybean caused by Phoma glycinicola. Online publication. United States Department of Agriculture. https://www.ars.usda.gov/ARSUserFiles/00000000/ opmp/Soybean\%20RLB\%20April\%202011.pdf

Hartman, G. L., and Sinclair, J. B. 1992. Cultural studies on Dactuliochaeta glycines, the causal agent of red leaf blotch of soybeans. Plant Dis. 76: 847-852.

Hartman, G. L., West, E. D., and Herman, T. K. 2011. Crops that feed the world 2. Soybean- worldwide production, use, and constraints caused by pathogens and pests. Food Secur. 3:5-17.

Hartman, G. L., and Sinclair, J. B. 1996. Red leaf blotch (Dactuliochaeta glycines) of soybeans (Glycine max) and its relationship to yield. Plant Pathol. 45:332-343.

Lamari, L. 2002. ASSESS: Image Analysis Software for Plant Disease Quantification. American Phytopathological Society, St. Paul, MN.

Levy, C. 1987. Aspects of morphology, cultural and pathogenic characteristics of the fungus, Pyrenochaeta glycines, causal agent of red leaf blotch of soybeans. Ph.D. thesis, University of Zimbabwe, Harare, Zimbabwe.

Levy, C., Mahuku, G. S., Tattersfield, J. R., and Cole, D. L. 1990. Method of assessment of red leaf blotch on soybeans used to evaluate cultivar susceptibility and chemical control. Crop Prot. 9:148-154.

Minitab. 2010. Minitab 17 Statistical Software. Minitab, Inc., State College, PA.

Nelson, B. 1985. Inoculum preparation of Sclerotinia sclerotiorum for infection of sunflower and other hosts. (Abstr.) Phytopathology 75:1333.

SAS Institute. 2008. SAS/STAT 9.2 User's Guide. SAS Institute, Inc., Cary, NC.

Sinclair, J. B. 1989. Threats to production in the tropics: Red leaf blotch and leaf rust. Plant Dis. 73:604-606.

Stewart, R. B. 1957. An undescribed species of Pyrenochaeta on soybean. Mycologia 49:115-117.

Tivoli, B., Baranger, A., Avila, C. M., Banniza, S., Barbetti, M., Chen, W., Davidson, J., Lindeck, K., Kharrat, M., Rubiales, D., Sadiki, M., Sillero, J. C., Sweetingham, M., and Muehlbauer, F. J. 2006. Screening techniques and sources of resistance to foliar diseases caused by major necrotrophic fungi in grain legumes. Euphytica 147:223-253.

USDA-ARS. 2017. Germplasm Resources Information Network. Online publication. United States Department of Agriculture-Agricultural Research Service, National Genetic Resources Program. National Germplasm Resources Laboratory, Beltsville, MD. http://www.ars-grin.gov/ 